DOI https://doi.org/10.18551/rjoas.2017-11.74

\title{
THE LINE OF VITAMINIZED BAKERY FOR THE REGIONS OF FAR NORTH
}

\author{
Verboloz E.I. ${ }^{*}$, Alekseev G.V., Doctor of Technical Sciences \\ Saint Petersburg State National Research University of Information Technologies, \\ Mechanics and Optics, Saint Petersburg, Russia
}

Savelev A.P., Graduate student Military Academy of Logistics, Saint Petersburg, Russia

Derkanosova A.A., Candidate of Technical Sciences Orinicheva A.A., Graduate student

Voronezh State University of Engineering Technologies, Voronezh, Russia

*E-mail: elenaverboloz@mail.ru

\begin{abstract}
Now marked out 11 categories of non-alimentary substances for which their pharmacological effect are proved (food fibers, oligosaccharides, phenolic compounds, polyunsaturated fatty acids, glycolipids, isoprenoids, vitamins, phospholipids and etc). At the same time, food engineering for health products and food products with specialized purposes are developing. To develop the domestic economy, the problem of complex processing of agricultural raw materials is urgent.
\end{abstract}

\section{KEY WORDS}

Bakery products, production, thermal energy, line of products, continuous cycle.

A constructive solution that partially solves the issue of the consistency of the individual stages of the baking process and the compact placement of individual assemblies is proposed.

Vitaminization with fish minced meat is ensured by the fact that in the line for baking goods with filling, containing forms made as separate elements, articulated by a flexible connection to form an endless belt, a heating element, a dough dispenser and mechanisms for preparing and removing molds in the form of levers with electromagnets placed in them. In addition, the individual elements are made in the form of hollow cylinders of non-magnetic material, the upper and lower parts of which are made through grooves with the upper and lower covers installed in them with the possibility of longitudinal displacement, and the annular substrate of ferromagnetic material placed between them; removing the pushers with electromagnetic actuators are installed with the possibility of reciprocating movement, and the mechanisms of preparation and removal of molds and reciprocating pushers with an electromagnet drive synchronized with each other, while the mechanism of removal of forms is synchronized with the filling dispenser installed above it.

Technical result during the using of the proposed line is provided by the implementation of separate elements in the form of hollow cylinders of non-magnetic material, in the upper and lower parts of which are made through grooves with upper and lower covers installed in them with the possibility of longitudinal displacement. The arrangement between these covers of an annular substrate of ferromagnetic material allows realizing in a single continuous production cycle the forming of test billets, filling of them and making the necessary final heat treatment. This is facilitated by the fact that for the preparation and removal of the covers, the pushers with electromagnetic drive are installed with the possibility of reciprocating movement. Since the mechanisms for the preparation and removal of molds and the reciprocating pushers with electromagnetic drive are synchronized with each other, the mechanism for removing the molds is synchronized with the filling dispenser installed above it. The bakery products meet the necessary quality requirements, and the time for their 
production is significantly reduced. The efficiency of the device is determined by the fact that the entire baking process up to obtaining the finished product is made in a continuous cycle on a single conveyor line. This ensures the natural synchronization of individual stages. On the other hand, this design allows more complete use of the heat energy of the tunnel kiln and significantly reduces the production area. In addition, the unification of individual parts of the device facilitates its manufacture and further reduces operational costs, for example, during the repairing process.

The main scheme of the line is presented on the Figure 1. Such line for baking products with a filling contains forms completed in as separated elements, articulated with a flexible connection to form an endless line 1, the heating element 2, the dough dispensers 3 and the filler dispenser 4 , the mold preparation mechanisms 5 and the mold removal mechanism 6 , the individual elements 1 being made in the form of hollow cylinders of nonmagnetic material, the upper and lower parts of which are made through grooves with the grooves the possibility of longitudinal displacement of the upper and lower covers, between which is placed an annular substrate of ferromagnetic material. For the preparation and removal of the covers, the electromagnetically driven pushers 7 are arranged for reciprocating movement, the preparation mechanism and the mold removal mechanism being in the form of levers with the electromagnets arranged therein and synchronized with each other and with the reciprocating pushers 7 , and the mechanism for removing the molds synchronized also with the filler dispenser installed above it.

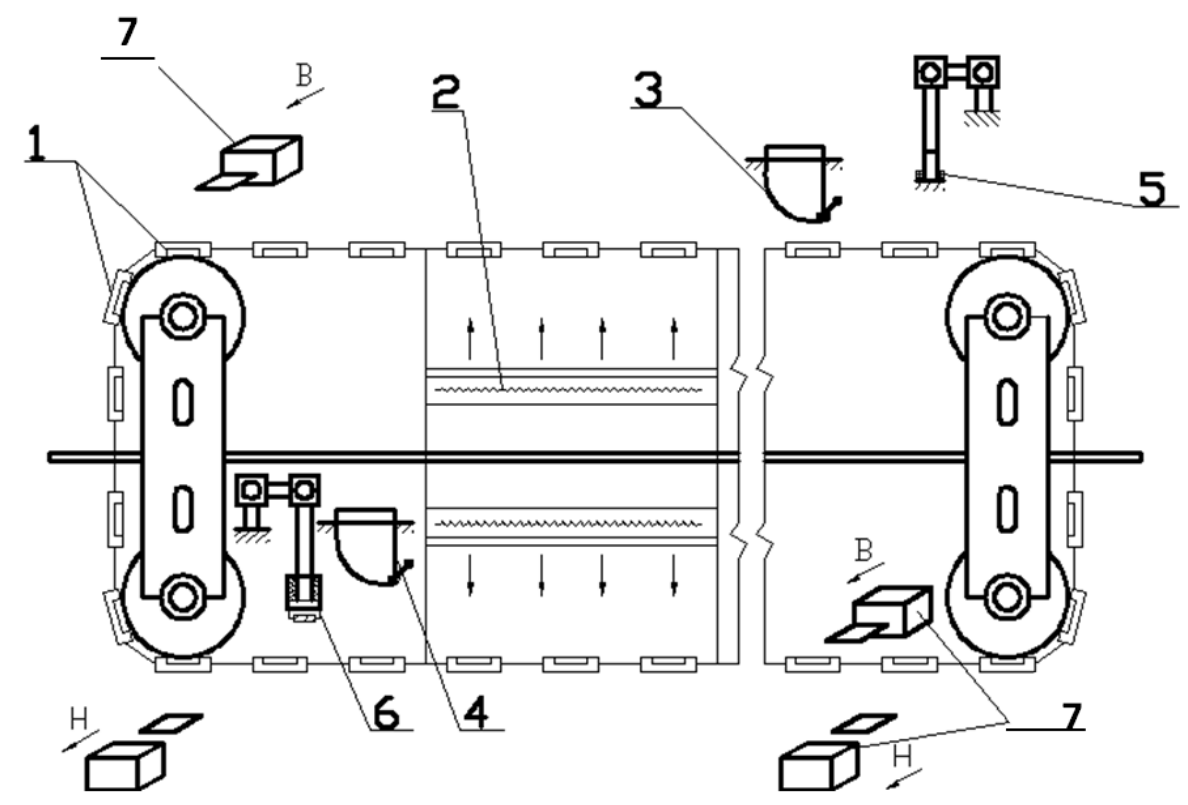

Figure 1 - The principal scheme of the line for baking products with filling: 1 - the line; 2 - the heating element; 3 - the dough dispenser; 4 - the filler dispenser; 5 - the mold preparation mechanisms; 6 the mold removal mechanism; 7 - the pusher

The baking line works as follows. When the endless belt 1 is moving along the upper transport section of the installation, a separate element of the tape 1 enters the area of the mechanism for preparing the molds 5 , made in the form of a hollow cylinder of non-magnetic material, the upper and lower parts of which are made through grooves with one in them with the possibility of longitudinal move of the bottom cover.

The mechanism for preparing the molds 5 places an annular substrate of a ferromagnetic material on this cover. With further transfer of the endless belt from the dough dispenser 3 , a certain dose of dough is placed on this substrate, which, filling the gaps, takes the form of a test billet, and then enters the area of action of the heating element 2. After the heat treatment of the test billet, the element 1 is moved to the zone of action of the first reciprocating pusher, which in the free slot of the cylinder places the top cover. When the 
element 1 is moved to the lower transport portion of the installation, the lower cover, on which the ferromagnetic annular substrate was previously supported, is removed to the zone of the second reciprocating pusher 7. Then, the removal mechanism of the molds 6 removes this ferromagnetic annular substrate, after which a certain amount of filling is placed on the test billet. The semi-finished product enters the zone of the heating element 2, where it passes the final heat treatment.

When the element 1 is moved to the zone of operation of the third and fourth reciprocating pushers 7 from the cylinder, the lid on which the finished article rests is removed and it is unloaded from the element 1 , and instead of this, at the same time, a lid is placed in the slots, 5 will place an annular substrate of ferromagnetic material. Then the cycle of baking is repeated. It is important that the synchronization of the mechanisms 5 and 6 with the pushers 7 makes it possible to provide a practically continuous movement of the mold in the form of separate elements articulated by a flexible connection to form an endless belt, and the synchronization of the mechanism for removing the molds also with the filler metering device installed above it provides baking products of required quality.

The described design of the device allows to obtain finished products in a single technological cycle with high quality and minimal use of production areas and energy resources, ensuring at the same time, through the unification of nodes, insignificant operating costs, for example, during repair and maintenance.

Successful operation of the described line for baking open bakery products filled with fish products requires careful calculation of its individual elements, including dispensers, the most critical part of which is a screw compressor.

Considering the given above data of the study of the structural and mechanical characteristics of combined fish-groats and fish-vegetable masses, which can be used as fillings, the following methodology for calculating the screw supercharger can be recommended.

The simplified linear theory of worm-blowers uses a model of the movement of the food medium between parallel plates. It is assumed that the environment has a linear viscosity, is incompressible, the process of displacement of the environment is isothermal and laminar. The channel of the screw feeder in this case is represented as a horizontal cylinder of rectangular cross section with one movable wall, the principle of inverted relative movement of the auger and auger channel is used (Fig. 2).

Let us also assume that the outer diameter of the auger and the inner diameter of the auger cylinder coincide, i.e. There is no gap in which there may be a reverse flow of material. The flow in this gap can be taken into account separately. Then the velocity of the upper plate in the rectangular channel.

$$
V_{z}=\frac{\pi D n}{60} \cos \varphi
$$

Where: $V z$ - the projection of the velocity of the points of the screw with $y=h$ on the axis $z$; $\mathrm{n}$ - angular velocity of the screw in revolutions per minute ; $\mathrm{D}$ - outer diameter of the auger; $f-$ the angle of the helix of the auger.

The equation of motion in the projections on the $z$ axis:

$$
\begin{aligned}
& \rho\left(\frac{\partial v_{z}}{\partial t}+v_{x} \frac{\partial v_{z}}{\partial x}+v_{y} \frac{\partial v_{z}}{\partial y}+v_{z} \frac{\partial v_{z}}{\partial z}\right)=-\frac{\partial P}{\partial z}+ \\
& +\left(\frac{\partial \tau_{x z}}{\partial x}+\frac{\partial \tau_{y z}}{\partial y}+\frac{\partial \tau_{z z}}{\partial z}\right)+\rho g_{z}
\end{aligned}
$$


The rheological equations of the Newtonian fluid in rectangular coordinates for this case (taking into account that the coefficient $\chi$ of bulk viscosity is 0 ) have the form:

$$
\begin{aligned}
& \tau_{x z}=\mu\left(\frac{\partial v_{z}}{\partial x}+\frac{\partial v_{x}}{\partial z}\right) \\
& \tau_{y z}=\mu\left(\frac{\partial v_{y}}{\partial z}+\frac{\partial v_{z}}{\partial y}\right) \\
& \tau_{z z}=\mu\left[\frac{\partial v_{z}}{\partial z}-\frac{2}{3}\left(\frac{\partial v_{x}}{\partial x}+\frac{\partial v_{y}}{\partial y}+\frac{\partial v_{z}}{\partial z}\right)\right]
\end{aligned}
$$

Where: $\tau_{x z}, \tau_{y z}, \tau_{z z}$ - components of the components of the tensor of tangential stresses (deviator of the stress tensor).

Let's substitute expressions (3) - (5) in equation (2) and take into account the following simplifications:

- in view of the stationarity of the flow $\frac{\partial v_{z}}{\partial t}=0$;

- in a plane-parallel channel model $v_{x}=v_{y}=0$;

- the geometry of the channel along the $z$ axis does not change, where $\frac{\partial v_{z}}{\partial z}=0$;

- the fluid is incompressible, where $\chi=0 ; \rho=$ const.;

- the horizontal channel, where $g_{z}=0$.

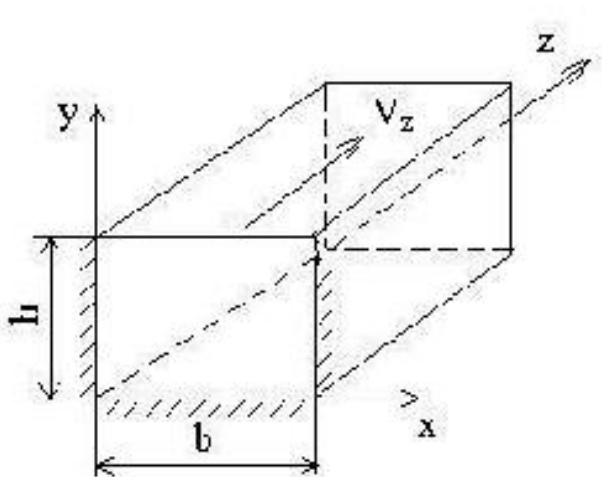

a)

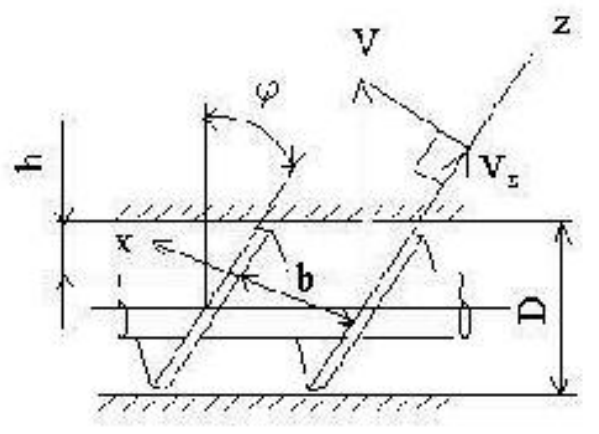

b)

Figure 2 - Schematic diagram of auger feeder

Taking into account the above simplifications, the differential equation of motion for the theory of worm-blowers will have the form:

$$
\frac{\partial^{2} v_{z}}{\partial x^{2}}+\frac{\partial^{2} v_{z}}{\partial y^{2}}=\frac{1}{\mu}\left(\frac{\partial P}{\partial z}\right)
$$


Let's suppose that for shallow and wide channels the flow velocity depends little on the coordinate $x$. Then equation (6) becomes even simpler and leads to a boundary-value problem of the form:

$$
\frac{d^{2} v_{z}}{d y^{2}}=\frac{1}{\mu}\left(\frac{\partial P}{\partial z}\right) ; v_{z}(0)=0 ; v_{z}(h)=V_{z}
$$

Solving this boundary-value problem, let's obtain an expression for the distribution of the flow velocities of the medium in the helical channel, as a function of the coordinate $y$ :

$$
v_{z}(y)=y\left(\frac{V_{z}}{h}\right)-\frac{y h-y^{2}}{2 \mu}\left(\frac{\partial P}{\partial z}\right)
$$

By integration, let's obtain a formula for constructing the discharge-pressure characteristic of a worm-blower:

$$
Q=b \int_{0}^{h} v_{z}(y) d y=\frac{V z b h}{2}-\frac{b h^{3}}{12 \mu}\left(\frac{\partial P}{\partial z}\right)
$$

Of course, in the derivation of the obtained formulas, significant simplifications were made, but the main regularities of worm-blowers in the food industry describe these dependencies quite satisfactorily, especially if the effective viscosity coefficient for a nonNewtonian food medium at a certain effective shear rate is used instead of the dynamic viscosity coefficient of the Newtonian fluid model, which especially important for example for fish minced meat and pastes.

After the additional integration, let us obtain a formula for the flow rate of the medium, caused by the pressure drop:

$$
Q_{1}=-\frac{b h^{3}}{12 \mu}\left(\frac{\partial P}{\partial z}\right)\left[1-\frac{192 h}{\pi^{5} b} \sum_{n=1,3,5}^{\infty} \frac{1}{n^{5}} \cdot \operatorname{th}\left(\frac{n \pi b}{2 h}\right)\right]
$$

To interpolate the values of the correction factors for other values of the ratio of the depth and width of the worm channel, it is possible to use the program in Mathcad and plot the graph (Fig. 3)

$$
\begin{aligned}
& \mathrm{N}:=50 \\
& \mathrm{f}(\mathrm{x}):=\frac{16 \cdot \sum_{\mathrm{n}=1}^{\mathrm{N}} \frac{1}{\mathrm{n}^{3}} \cdot \frac{1-\cos (\mathrm{n} \cdot \pi)}{2} \cdot \tanh \left(\frac{\mathrm{n} \cdot \pi \cdot \mathrm{x}}{2}\right)}{(\pi)^{3} \cdot \mathrm{x}} \\
& \mathrm{fl}(\mathrm{x}):=\left[1-\frac{192 \cdot \mathrm{x}}{\pi^{5}} \cdot\left(\sum_{\mathrm{n}=1}^{\mathrm{N}} \frac{1}{\mathrm{n}^{5}} \cdot \frac{1-\cos (\mathrm{n} \cdot \pi)}{2} \cdot \tanh \left(\frac{\mathrm{n} \cdot \pi}{2 \cdot \mathrm{x}}\right)\right)\right]
\end{aligned}
$$

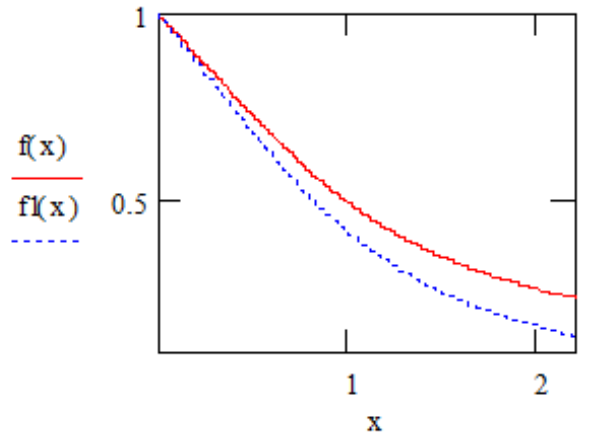

Figure 3 - The dependence of the refinement coefficients on the ratio of depth and width of the channel

The obtained results allow to design screw dispensers for completing the proposed line and to ensure the release of fortified bakery products in the form of open pies. 


\section{REFERENCES}

1. Romanchikov S.A. Perspektivy razvitiya modificirovannyx vidov prodovol'stviya [Tekst] / S.A. Romanchikov, A.V. Grishin, E.M. Sidorov// Sbornik Materialov IX Mezhdunarodnoj zaochnoj nauchno-prakticheskoj konferencii: «Problemy vosproizvodstva obshhestvennogo kapitala v kontekste global'nogo neravenstva» (Krasnodar, 15.07.2014) FGBU «Rossijskoe ehnergeticheskoe agentstvo» 2014. S. 131-138.

2. Romanchikov S.A. Innovacionnye resheniya $v$ sfere proizvodstva produkcii agropromyshlennyx predpriyatij [Tekst] / A.A. Sychev, S.A. Romanchikov // Sbornik nauchnoj konferencii s mezhdunarodnym uchastiem «Nedelya nauki v SPBPU» (SanktPeterburg 14-19.11.2016 g.)- ch. 1 CPb.: Izd-vo «Sankt-Peterburgskij politexnicheskij universitet Petra Velikogo» 2016. S. 61-63.

3. Akulich A.A., Vasyukova A.G., Nekrasova S.O. Vliyanie tradicionnyx sposobov teplovoj obrabotki na soxrannost' belkovyx veshhestv ryby // Industrial'nye texnologii proizvodstva produkcii obshhestvennogo pitaniya. - M.: $1985 / 1987 /$. - s. 158-162.

4. Aret V.A., Azarov B.M. Inzhenernaya reologiya pishhevyx proizvodstv.-M.: MTIPP, 1978.$112 \mathrm{~s}$.

5. Artemenko V.E., Zdobnov A.I. Razrabotka texnologicheskix sxem proizvodstva myasnyx i rybnyx izdelij s ehmul'siyami na osnove ovoshhej // Uskorenie nauchno-texnicheskogo progressa v obshhestvennom pitanii. - Kiev, 1987. - Vyp. 22. - s. 86-89.

6. Berezovikova I.P. Razrabotka texnologii kulinarnoj produkcii s vysokim soderzhaniem pishhevyx volokon: Avtoref. dis. ... kand. texn. nauk /LIST im. F. Ehngel'sa. - L., 1989. $16 \mathrm{~s}$.

7. Bidenko M.S., Artyuxova S.A. Perspektivy razvitiya texnologii konservov iz ob"ektov okeanicheskogo promysla. - Kaliningrad: AtlantNIRO, 1987. - s. 4-10. 